\title{
Bilirubin binding in premature infants from birth to 3 months
}

\author{
D A RITTER AND J D KENNY \\ Department of Pediatrics, Temple University School of Medicine, Philadelphia, Pennsylvania, United States \\ of America
}

SUMMARY The effect of postnatal age on serum bilirubin binding measurements was studied prospectively in extremely premature infants of 25-28 weeks' gestation. Serum was obtained from 10 infants at birth, 2-4 days of age, 1 week, 2 weeks, 4 weeks, 8 weeks, and 10-13 weeks. Using peroxidase oxidation, the apparent unbound bilirubin concentration (AUBC) was measured and plotted versus the molar ratio of total bilirubin:albumin $(R)$ using the empiric power curve $A U B C=a R^{b}$. The apparent unbound bilirubin concentration at bilirubin:albumin ratio 0.6 was used to compare relative binding ability among specimens. This value, as well as the apparent association constants, showed dramatic deterioration after birth, which persisted without improvement until 8 weeks of age. This pattern of recovery correlated in general with the resolution of clinical problems. Binding values equivalent to adult serum were achieved by $10-13$ weeks. This study emphasises that diminished bilirubin binding by the sera of premature infants can persist for a prolonged period.

The mechanism of altered albumin-bilirubin binding in neonatal serum has remained an enigma despite extensive studies. It is known that infant serum binds bilirubin only a half to a third as effectively as adult serum. ${ }^{1-3}$ At the time of birth, bilirubin binding by infant serum is equivalent at all gestational ages from 26-42 weeks ${ }^{2}$ but can be adversely affected during the first postnatal week by illness ${ }^{4-7}$ and certain drugs. ${ }^{8}$

There is no information available on the long term postnatal course of binding measurements in the preterm infant. This may have importance for the management of prolonged unconjugated hyperbilirubinaemia and give insight into the resolution of infant binding deficiencies.

For these reasons, we have prospectively investigated the ability of serum from a group of very premature infants (25-28 weeks' gestation) to bind bilirubin during the first 3 months of life. Measurements were made serially and related to the clinical course.

\section{Materials and methods}

Patient population. Ten premature infants were studied throughout their admission to hospital until discharged home. To be included in this prospective study the following criteria were used: (1) gestational age $\leqslant 28$ weeks as assessed by maternal dates, obstetrical ultrasound scanning, and clinical examination; ${ }^{9}$ (2) appropriate in utero growth for gestational age: ${ }^{10}(3)$ no evidence of congenital anomalies or viral infection; (4) negative direct Coombs test; and (5) informed consent from one or both parents.

The mean (SD) birth weight was 860 (140) $\mathrm{g}$ (range $660-1060 \mathrm{~g}$ ) with a mean gestational age of $26 \cdot 3$ weeks \pm 1 SD (range 25-28 weeks). One infant was born precipitously at home $(660 \mathrm{~g}, 25$ weeks), arriving at Temple University Hospital at roughly 15 minutes of age. The remaining nine infants were delivered at our hospital, receiving median Apgar scores of 3 and 6 at one and five minutes, respectively.

All infants required mechanical ventilation. Five infants had hyaline membrane disease; the others had respiratory insufficiency of prematurity. Bronchopulmonary dysplasia occurred in five infants. The Table summarises the mean length of respiratory support and the presence of additional medical problems. Drugs used when indicated were ampicillin, gentamicin, methicillin, aminophylline, phenobarbitone, frusemide, and indomethacin. The diluents for these drugs did not contain preservatives. 
Table Clinical characteristics of the patient population

\begin{tabular}{|c|c|}
\hline & $\begin{array}{l}\text { Patients } \\
(n=10)\end{array}$ \\
\hline Birth weight $(g)^{*}$ & $860 \cdot 0(140)$ \\
\hline Gestational age (weeks) ${ }^{*}$ & $26 \cdot 3$ (1) \\
\hline $\operatorname{Sex}(M / F)$ & $4 / 6$ \\
\hline \multicolumn{2}{|l|}{ Apgar score: } \\
\hline 1 minute $\neq$ & $3(2-7)$ \\
\hline 5 minutes拉 & $6(2-8)$ \\
\hline \multicolumn{2}{|l|}{ Respiratory support: } \\
\hline Mechanical ventilation & 10 \\
\hline Duration of mechanical ventilation (days) $\ddagger$ & $24(1-67)$ \\
\hline $\begin{array}{l}\text { Length of time in fractional } \\
\text { inspiratory oxygen }>21 \% \text { (days) } \ddagger\end{array}$ & $36(15-78)$ \\
\hline Maximal supplemental oxygen $(\%) \ddagger$ & $53(30-100)$ \\
\hline Patent ductus arteriosus: & 6 \\
\hline Indomethacin treatment & 4 \\
\hline Necrotising enterocolitis & 1 \\
\hline \multicolumn{2}{|l|}{ Intraventricular haemorrhage: } \\
\hline None & 8 \\
\hline Grade $1-3$ & 0 \\
\hline Grade 4 & 2 \\
\hline Proven sepsis & 1 \\
\hline
\end{tabular}

*Values are mean (SD).

tExcludes one infant born at home.

$\ddagger$ Values are median (range).

All 10 infants developed unconjugated hyperbilirubinaemia during the first week of postnatal life. The mean (SD) maximum total bilirubin was 106 (24) $\mu \mathrm{mol} / \mathrm{l}(6 \cdot 1(1.4) \mathrm{mg} / 100 \mathrm{ml})$, occurring from the 3rd to the 7th day of life. Only one infant received an exchange transfusion. Phototherapy was given for a median of five days (range three-19). Conjugated hyperbilirubinaemia did not occur in any infant throughout the admission to hospital, with all direct bilirubin values being $\leqslant 17 \mu \mathrm{mol} / \mathrm{l}$ (1 $\mathrm{mg} / 100 \mathrm{ml}$ ).

Hyperalimentation was used for nutritional support when necessary. Intravenous lipid was given to seven infants. It was infused over 18-20 hours at a dose of $1-2 \mathrm{~g} / \mathrm{kg} / \mathrm{day}$. Any serum samples drawn for bilirubin binding studies were obtained three to four hours after stopping the infusion of lipid. Full enteral nutrition was achieved by a median of 20 days (range eight-45). By the time of discharge at 10-13 weeks all infants were free of supplemental oxygen and growing well on standard milk formula, weighing at least $2160 \mathrm{~g}$.

Bilirubin binding studies. Serum was obtained at the time of birth (cord blood), 2-4 days of age, 1 week, 2 weeks, 4 weeks, 8 weeks, and predischarge at 10-13 weeks. Serum was protected from light and stored at $-4^{\circ} \mathrm{C}$ until processed.

Albumin concentration was measured by a standard colorimetric method. ${ }^{11}$ Total bilirubin concentration was measured spectrophotometrically. ${ }^{12}$ The apparent unbound bilirubin concentration
(AUBC) was determined by horseradish peroxidase oxidation ${ }^{12}$ at $25^{\circ} \mathrm{C}$ using a Coleman 124 recording spectrophotometer. Bilirubin titration curves were prepared by adding small amounts of an alkaline bilirubin (Sigma, St Louis) solution to aliquots of serum. A range of 10-20 titration points was performed with each specimen. The curves were analysed as described previously ${ }^{2}$ according to the empiric power curve equation $\mathrm{AUBC}=\mathrm{aR}^{\mathrm{b}}$, where $\mathrm{R}$ is the molar ratio of total bilirubin:albumin. The apparent association constants for the primary and secondary bilirubin binding sites were estimated from Scatchard plots using a standard graphic interpolation method. ${ }^{13}$

Mean (SD) rate constant $(\mathrm{Kp})$ for the enzymatic reaction was $2.75(0.50) \triangle \mathrm{A} / \mu \mathrm{mol} / \mathrm{l} / \mathrm{min}$. Coefficients of variation for triplicate determinations were $1.7 \%$ for total bilirubin and $5.3 \%$ for apparent unbound bilirubin concentration.

Statistical analysis. Data are expressed as mean (SEM) or as median with range or percentiles. All comparisons between groups were made using the paired or unpaired Student $t$ test or the Wilcoxon rank sum test where appropriate. Curvilinear and linear regression analysis was performed using the least squares method with calculation of the appropriate correlation coefficients. For all statistical tests the null hypothesis was considered to be rejected if $\mathrm{p}<0.05$.

\section{Results}

Titration curves of serum are presented as direct plots of the apparent unbound bilirubin concentration (AUBC) against the molar ratio of total bilirubin:albumin (R). By using the molar ratio the effect of differences in albumin concentration among the samples was removed. In comparing titration curves a higher apparent unbound bilirubin concentration at any specified molar ratio indicates diminished binding. Figure 1 presents the results obtained on serum at birth, 1 week, and 10-13 weeks of age. The shape of the titration curves apparently changes with advancing postnatal age. Using both paired and unpaired testing, the apparent unbound bilirubin concentration at birth and 1 week were significantly different at molar ratios of $0.4,0.6,0.8$, and 1.0 (all $\mathrm{p}<0.02$ ), indicating a deterioration in the binding ability of serum at one week compared with the time of birth. By 10-13 weeks postnatally the apparent unbound bilirubin concentration at all values of the molar ratio $(0 \cdot 2$, $0 \cdot 4,0 \cdot 6,0 \cdot 8$, and $1 \cdot 0$ ) had significantly improved compared with both previous times $(\mathrm{p}<0.05$ in all cases). 


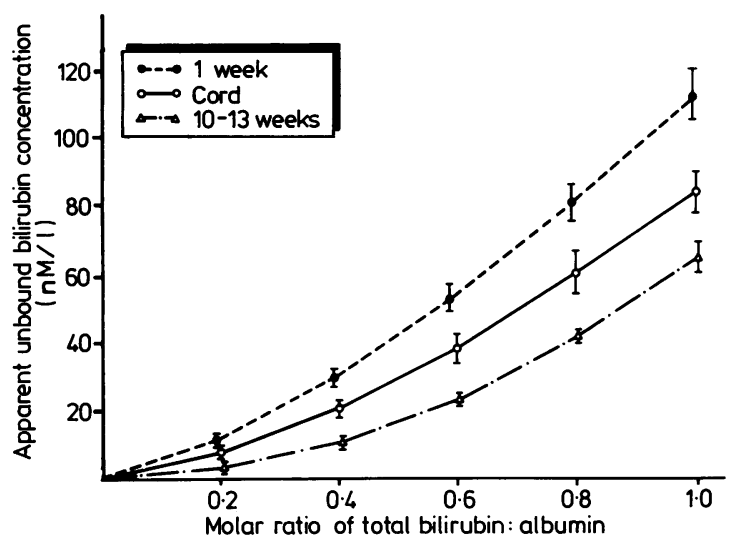

Fig. 1 Titration curves of serum from premature infants (25-28 weeks' gestation) at birth, 1 week, and 10-13 weeks postnatally. Direct plot of apparent unbound bilirubin concentration against the molar ratio of total bilirubin:albumin. Values are mean (SEM).

Figure 2 depicts the serial measurements of titration values, albumin concentrations, and the primary association constants. We have arbitrarily selected the titration value of apparent unbound bilirubin concentration at molar ratio of 0.6 to graphically show the pattern of these values. Plotted as a function of postnatal age, the apparent unbound bilirubin concentration at molar ratio of
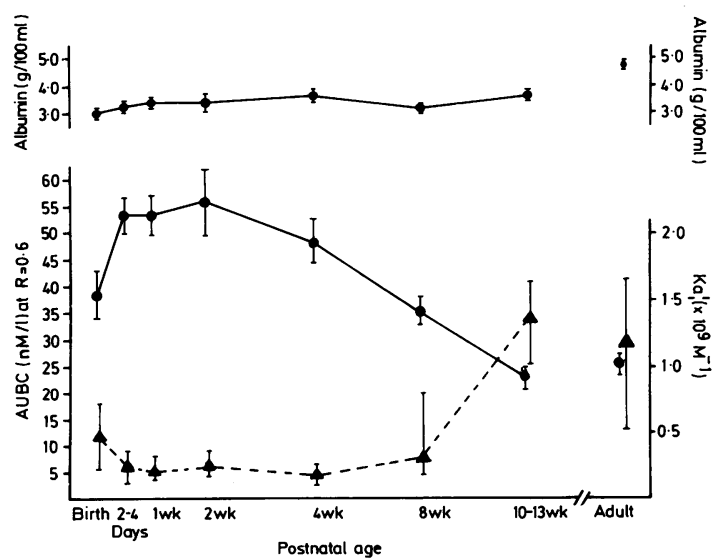

Fig. 2 Postnatal course of serial measurements of albumin-bilirubin binding. Values are mean (SEM) for albumin and apparent unbound bilirubin concentration $(A U B C)$ at molar ratio $(R)$ of 0.6 (shown - ). Values for primary association constant $\left(K a_{l}^{l}\right)$ (shown $\left.\mathbf{\Delta}---\mathbf{\Delta}\right)$ are median (25-75 percentile). Adult data are obtained from previous work. $^{2}$

Conversion: traditional units to $S I-$ Albumin: $1 \mathrm{~g} / 100 \mathrm{ml}=145 \mu \mathrm{mol} / 1$
$0 \cdot 6$ increased significantly from a mean (SEM) of $38.4(4.5) \mathrm{nM} / \mathrm{l}$ at birth to $53.4(3.3) \mathrm{nM} / \mathrm{l}$ at $2-4$ days of age $(\mathrm{p}<0.05)$. It remained at this concentration until 8 weeks, when the mean value declined to 35.5 $(2.7) \mathrm{nM} / 1$. It improved further to $23.3(1.2) \mathrm{nM} / 1$ at 10-13 weeks $(\mathrm{p}<0.005$ compared with birth and 8 weeks). This value was similar to the mean apparent unbound bilirubin concentration at molar ratio of 0.6 previously noted in adult serum. ${ }^{2}$ This pattern of deterioration and improvement in titration values was identical for the apparent unbound bilirubin concentration at all values of the molar ratio $(0 \cdot 2$, $0 \cdot 4,0 \cdot 6,0 \cdot 8$, and $1 \cdot 0$ ).

The postnatal course of serum albumin concentrations showed a gradual rise from 435 (SEM 14) $\mu \mathrm{mol} / \mathrm{l}(3(0 \cdot 01) \mathrm{g} / 100 \mathrm{ml})$ at birth to 537 (SEM 14) $\mu \mathrm{mol} / \mathrm{l}(3 \cdot 7(0 \cdot 01) \mathrm{g} / 100 \mathrm{ml})$ at 3 months $(\mathrm{p}<0.005)$.

Both the apparent primary $\left(\mathrm{Ka}_{1}^{1}\right)$ and secondary $\left(\mathrm{Ka}_{2}^{1}\right)$ association constants declined after birth during the first month of life, then improved toward adult values by $10-13$ weeks. The median primary association constant at birth was $0.47 \times 10^{9} \mathrm{M}^{-1}$ (range $0.03-1.73 \times 10^{9} \mathrm{M}^{-1}$ ) and fell during the first 4 weeks (all $\mathrm{p}<0.05$ compared with birth). The median primary association constant at 10-13 weeks $\left(1.37 \times 10^{9} \mathrm{M}^{-1}\right)$ was not significantly different from that for adult serum but was improved over all previous infant measurements ( $\mathrm{p}<0.01$ in all cases). There was a significant linear correlation between the apparent unbound bilirubin concentration at molar ratio of 0.6 and the primary association constant $(\mathrm{r}=0.62, \mathrm{p}<0.001)$.

The secondary association constant had a similar postnatal pattern. The secondary association constant at birth (median $1.30 \times 10^{7} \mathrm{M}^{-1}$ ) declined to a stable level over the first month $\left(0.78-0.84 \times 10^{7} \mathrm{M}^{-1}\right)$ and then rose at 10-13 weeks of age (median $\left.1.75 \times 10^{7} \mathrm{M}^{-1}\right)$ to equal that found in adult serum.

\section{Discussion}

We have studied postnatal changes in albuminbilirubin binding in sera from sick, extremely premature infants. There was a prolonged period of diminished binding lasting one month. A subsequent dramatic improvement occurred so that bilirubin binding was equal to that of adult serum by 3 months.

These changes in binding must be interpreted in view of the infants' clinical state. Cashore ${ }^{6}$ and Ebbesen $^{57}$ have shown that bilirubin binding to albumin could be affected in preterm infants by the presence of illness; altered binding began to show improvement when the illness resolved, but their infants were followed for only six to 10 days after birth. ${ }^{6}$ The infants in our study were less mature at 
birth and had a more prolonged course of illness than the previously reported infants. In general, most of our infants 'turned the corner' toward a more healthy state between 4 and 8 weeks. At 4 weeks we would consider that nine out of 10 of our infants were still ill in that six were receiving ventilator/oxygen support, three were being treated for suspected or proven sepsis, and two were recovering from episodes of intestinal dysfunction. By 8 weeks most of these problems had resolved so that only two were receiving supplemental oxygen for bronchopulmonary dysplasia, and all were tolerating full enteral feedings. Thus it seems that the improved bilirubin binding that occurred at 8 weeks may have been due to a resolution of factors related to illness. However, it could be totally independent of illness and be a coincidental postnatal effect. To answer this question would require a similar long term serial study in preterm infants who have even more chronic disease.

By 3 months the serum of our preterm infants had binding characteristics indistinguishable from that of adult sera. Kapitulnik has followed healthy term infants and shown that their binding abnormality resolved by $2-5$ months. ${ }^{3}$ This suggests that resolution of the profound binding abnormality present at birth in infants of all gestational ages is related to the postnatal passage of time rather than postconceptional age.

The changes in binding that we observed cannot be explained as an effect of phototherapy, ${ }^{14}$ drugs, ${ }^{8}$ or intravenous lipid. Lipid infusions were given at doses and rates known to have minimal effects on serum free fatty acids and cholesterol concentrations, ${ }^{15}$ and serum was drawn several hours after completion of the dose. Moreover, only one infant was receiving lipid at 4 weeks.

The aetiology of the diminished infant albuminbilirubin binding remains unclear. It is not due to a difference in physical or immunologic properties of infant albumin. ${ }^{16}$ It is probably due to a yet unidentified factor that attaches to the bilirubin binding site or alters the spatial conformation of the albumin molecule. ${ }^{5}$ Our results support the observation that binding affinity at both bilirubin sites is reduced after birth. Recent evidence that pregnant women also have diminished bilirubin binding ${ }^{17} 18$ suggests that the responsible factor might be passed transplacentally. While we have not elucidated the mechanism of the altered binding, we have shown that the resolution of the process in preterm infants may require a much longer time than previously suspected.

The correlation between any measured binding variable and kernicterus proved by autopsy is weak, ${ }^{19-21}$ making the direct clinical application of these binding measurements difficult. The current understanding of the relation between albuminbilirubin binding and integrity of the blood-brain barrier in the pathogenesis of kernicterus has been extensively reviewed. ${ }^{22}$ Much more information is needed on all facets of bilirubin transport and cellular uptake before a complete understanding of kernicterus can be achieved. In view of our data, however, it seems prudent to consider bilirubin a continued potential neurotoxin in preterm infants with both prolonged illness and prolonged or recurrent unconjugated hyperbilirubinaemia.

In summary, for sick preterm infants we have shown that: (1) binding studies on cord blood are not reflective of subsequent binding; (2) diminished binding can persist for as long as 4-8 weeks, perhaps to ongoing illness; and (3) that improvement eventually occurs with binding studies equal to that of adult serum by 3 months of age.

\section{References}

${ }^{1}$ Alayoff F, Kapitulnik J, Konijn A, Kaufmann NA, Blondheim SH. Bilirubin binding capacity of albumin isolated from cord-blood serum is less than from serum of adults. Clin Chem 1980;26:738-40.

2 Ritter DA, Kenny JD. Influence of gestational age on cord serum bilirubin binding studies. $J$ Pediatr 1985;106:118-21.

${ }^{3}$ Kapitulnik J, Horner-Mibashan R, Blondheim SH, et al. Increase in bilirubin-binding affinity of serum with age of infant. J Pediatr 1975;86:442-5.

${ }^{4}$ Cashore WJ, Oh W, Brodersen R. Reserve albumin and bilirubin toxicity index in infant serum. Acta Pediatr Scand 1983;72:415-9.

5 Ebbesen F, Brodersen R. Risk of bilirubin acid precipitation in preterm infants with respiratory distress syndrome: considerations of blood/brain bilirubin transfer equilibrium. Early Hum Dev 1982;6:341-55.

6 Cashore WJ, Horwich A, Laterra J, Oh W. Effect of postnatal age and clinical status of newborn infants on bilirubin-binding capacity. Biol Neonate 1977;32:304-9.

${ }^{7}$ Ebbesen F, Nyboe J. Postnatal changes in the ability of plasma albumin to bind bilirubin. Acta Pediatr Scand 1983;72:665-70.

${ }^{8}$ Brodersen R. Competitive binding of bilirubin and drugs to human serum albumin studied by enzymatic oxidation. J Clin Invest 1974;54:1353-64

9 Ballard JL, Novak KK, Driver M. A simplified score for assessment of fetal maturation of newly born infants. $J$ Pediatr 1979;95:769-74.

${ }^{10}$ Lubchenco L, Hansman C, Boyd E. Intrauterine growth in length and head circumference as estimated from live births at gestational ages from 26 to 42 weeks. Pediatrics 1966;37:403-8.

11 Doumas BT, Watson WA, Biggs HG. Albumin standards and the measurement of serum albumin with bromcresol green. Clinica Chimica Acta 1971;31:87-96.

12 Jacobsen J, Wennberg RP. Determination of unbound bilirubin in the serum of newborns. Clin Chem 1974;20:783-9.

${ }^{13}$ Berson SA, Yalow RS. Quantitative aspects of the reaction between insulin and insulin-binding antibody. J Clin Invest 1959;38:1996-2016.

${ }^{14}$ Ebbesen F. The relationship between serum bilirubin and reserve albumin for binding of bilirubin during phototherapy of preterm infants. Acta Pediatr Scand 1981;70:405-7.

15 Kao LC, Cheng MH, Warburton W. Triglycerides, free fatty acids, free fatty acids/albumin molar ratio, and cholesterol levels 


\section{Ritter and Kenny}

in serum of neonates receiving long-term lipid infusions: controlled trial of continuous and intermittent regimens. J Pediatr 1984;104:429-35.

${ }^{16}$ Gitzelmann-Cumarasamy N, Gitzelmann R, Wilson K, Kuenzle CC. Fetal and adult albumins are indistinguishable by immunological and physiochemical criteria. Proc Natl Acad Sci USA 1979;76:2960-3.

17 Järnerot G, Anderson S, Esbjörner E, Sandström B, Brodersen R. Albumin reserve for binding of bilirubin in maternal and cord serum under treatment with sulphasalazinc. Scand $J$ Gastroenterol 1981:16:1049-5.

${ }^{18}$ Ritter DA, Gabai BR, Kenny JD. Diminished bilirubin binding by the serum of pregnant women. Obstet Gynecol 1985;65: 633-6.

${ }^{19}$ Ritter DA, Kenny JD, Norton HJ, Rudolph AJ. A prospective study of free bilirubin and other risk factors in the developmen of kernicterus in premature infants. Pediatrics 1982;69:260-6.

${ }^{20}$ Cashore WJ, Oh W. Unbound bilirubin and kernicterus in low-birth-weight infants. Pediatrics 1982;69:481-5.

21 Zamet $\mathrm{P}$, Nakamura H, Perez-Robles S, et al. The use of critical levels of birth weight and "free bilirubin" as an approach for prevention of kernicterus. Biol Neonate 1975;26:274-82.

22 In: Levine RL, Maisels MJ, eds. Hyperbilirubinemia in the Newborn, report of the Eighty-Fifth Conference on Pediatric Research. Columbus, Ohio: Ross Laboratories, 1983.

Correspondence to Dr Ritter, Department of Neonatology, St Marys Hospital Medical Center, 707 South Mills Street, Madison, Wisconsin 53715, USA.

Received 15 November 1985 